Borneo Journal of Sciences and Technology, Volume (2), Issue (1), Pages: 48-57

DOI: https://doi.org/10.35370/bjost.2020.2.1-09

e-ISSN: 2672-7439

(c) 2018, UCTS Publisher.

Submitted: $6^{\text {th }}$ November $2019 \quad$ Accepted: $5^{\text {th }}$ December $2019 \quad$ Published: $31^{\text {th }}$ January 2020

\title{
An Energy-efficient Smart Street Lighting System with Adaptive Control based on Environment
}

\author{
${ }^{1}$ Kee Keh Kim, ${ }^{2}$ Simon Lau Boung Yew, and ${ }^{1}$ Mohamad Hafizan Affandi \\ ${ }^{1}$ School of Engineering and Technology, University College of Technology Sarawak, Sibu, Sarawak, \\ Malaysia. \\ ${ }^{2}$ Faculty of Engineering and Science, Universiti Tunku Abdul Rahman Bandar Sungai Long, Kajang, \\ Malaysia.
}

\begin{abstract}
Nowadays, most street lighting consumes high electrical power due to inefficient design. Energy efficiency and ease of maintenance with minimal involvement of manual work in street lights management are two top priorities of a smart city. To fulfil these purposes, the project aims to design and develop a smart street lighting system based on wireless sensing network technology and a novel adaptive control mechanism for the benefits of energy-saving and ease of maintenance. Experimental results show up to $48 \%$ potential energy saving compared to a conventional street lighting system.
\end{abstract}

Keywords: Street Lighting, Energy Efficiency, Wireless Sensing Network, Control Mechanism.

\section{INTRODUCTION}

A smart city refers to a city designated to incorporate ICT to enhance the quality of life and performance of public services. It includes the reduction of the consumption of resources, wastage and overall costs [1]. There is an urgent need to add more intelligence to the technological infrastructures and services in smart cities of tomorrow to optimise public resources. Street lighting is an essential part of a smart city that lights up the city in the darkness, for the safety of road users and to maintain an attractive appearance of the city. At the same time, studies have shown that public lighting can reduce crime by up to $20 \%$ and traffic accidents by up to $35 \%$ [2].

However, street lighting can consume up to $53 \%$ of the municipality's energy consumption that typically cost $35-45 \%$ of a municipality's utility budget [3]. Furthermore, $30-60 \%$ of overall carbon emissions are contributed by street lighting that causes the greenhouse effect[4]. According to the International Energy Agency, the overall demand for lighting will be $80 \%$ higher by 2030 than in 2005 [2]. It is projected that 5 billion people (about $60 \%$ of the world's population) will live in cities by 2050[2]. Hence, street lighting energy consumption will be an increasingly significant portion of cities' energy use and a growing burden on municipal budgets.

Conventional street light systems which are currently still prevalent in developing countries suffer from high electricity consumption due to inefficient design and causing environmental issues with escalating $\mathrm{CO}_{2}$ emissions. In Malaysia, many existing street lighting systems are found to incur relatively high energy consumption and maintenance costs, as compared to more energy-efficient systems used in developed countries. The systems still operate based on ON/OFF switch, the timer-controlled or light-activation sensor to automate the switching operations [5].

Majority of the cost of street lighting stems from the maintenance and operational expenses, instead of the capital costs (hardware costs). For instance, the total cost of a typical street lighting installation over 25 years is split as follows: $85 \%$ maintenance/operation (including power supply) and 15\% capital cost [6]. Therefore, energy consumption reduction and minimising the maintenance cost become the primary considerations for the design of street lighting system.

The key contribution of this project is the design and development of an integrated smart street lighting system based on wireless sensor network (WSN) technology that achieves energy efficiency, ease of use and asset management. The street lighting system in this project requires a real-time control mechanism taking into consideration environmental condition. For instance, the street lights would shut off during the daytime but can be switched on in cloudy weather with low light intensity to ensure the safety of road users. On the other hand, the street lighting in the nighttime operates under controlled time management with 
An Energy-efficient Smart Street Lighting System with Adaptive Control based on Environment

differing levels of traffic intensity. Besides, a motion detector is used to detect pedestrian traffic or the moving vehicles in the control mechanism to adapt and control energy usage for energy-saving purpose without compromising road safety.

In this system, the use of energy-efficient LED lighting and the adaptive control of illumination level by Pulse Width Modulation (PWM) signal ensures energy efficiency. The LED light source features low energy consumption and long lifespan. In this project, the nRF24L01wireless modules from Nordic are used for the implementation of WSN. The ATMEGA 328P microcontroller is used as the central processor to process the sensors environmental parameters and control the output devices accordingly. The sensors include the motion sensors, rain sensors, LightDependent-Resistant (LDR) sensors, and current sensors. As indicated by the experimental results presented in Section IV, the proposed system has the saving potential of electrical energy up to $48 \%$. Thus, it can potentially cut the municipal budget while reducing harmful carbon emissions.

The rest of this paper is structured as follows. Firstly, a detailed literature review of the current state-of-the-art of the related field is summarised. Secondly, the system architecture, design, hardware components control algorithm are explained in detail. Thirdly, the design and operation of an integrated Smart Street Light Asset Maintenance System are presented. Fourthly, the results of a case study of implementing the adaptive control of the street lights with the potential energy saving and ease of maintenance are discussed. Lastly, the current work is concluded, and the future research direction is proposed.

\section{LITERATURE REVIEW}

In Malaysia, street lighting systems must comply with the rules and regulations set by the Public Works Department, according to the Malaysian standards [7]. As outlined in MS852 Part 1 for the specification of street lighting brightness, the street light is not allowed to turn OFF in any situation, even in low traffic condition [8].

There are various design considerations proposed by researchers on street lighting control systems. Bellido et al. proposed the use of wireless communication over the Digital Addressable Lighting Interface (DALI) protocol to control street lighting [9]. The proposed design consists of sensor nodes placed at each street pole while a receiver node acted as the central station. Data from each receiver node are redirected to the Control Centre via GPRS. Fernandes et al. adopted a flexible WSN which offers the simplicity in hardware, reliable performance, expandability and flexibility for smart lighting applications [10]. WSNs are composed of nodes that make up a self-regulating group, and each has the function assigned to perform in the network, as depicted in Figure 1. Coordinator nodes, also known as fullfunction devices (FFD), are always singular and have exclusive roles in WSNs. They are in charge of setting up the network size, the personal area network (PAN) wireless nodes work on, and assign other router nodes (with end devices attached) nodes with individual addresses for recognition and wireless communication purposes. In general, coordinator nodes supervise the wireless network condition. In case of any node detaches, the coordinator node selects a different routing path to convey the data [11]. The proposed design is validated in terms of the average delay of data delivery via the network. The benefits of a smart city concept, i.e. reducing costs and enhanced supervision benefits are manifested via the sharing of the communication network between street lighting and advanced metering infrastructure (AMI) networks.

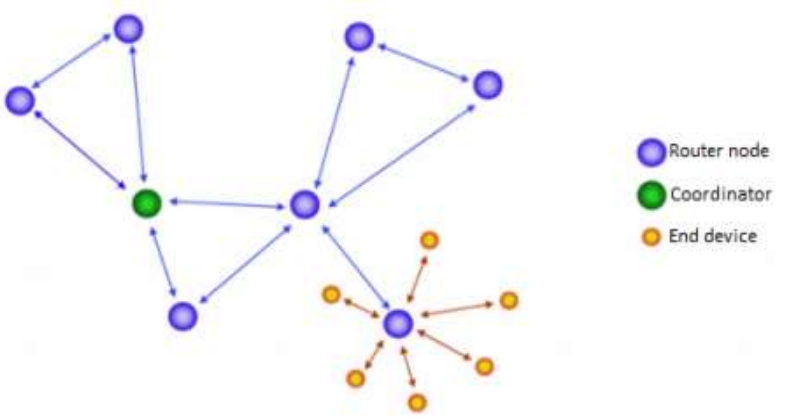

Figure 1: Wireless Sensor Network [11]

Meanwhile, most of the street lighting systems use mesh network as a communication network due to the advantages of self-healing and self-configuration [12]. Elejoste et al. proposed the use of a mesh network for the communication network between the streetlights and the central controller unit [13]. The smart streetlight system synchronises the behaviour to collect data from the environment and corresponds with the central controller unit, as depicted in Figure 2.

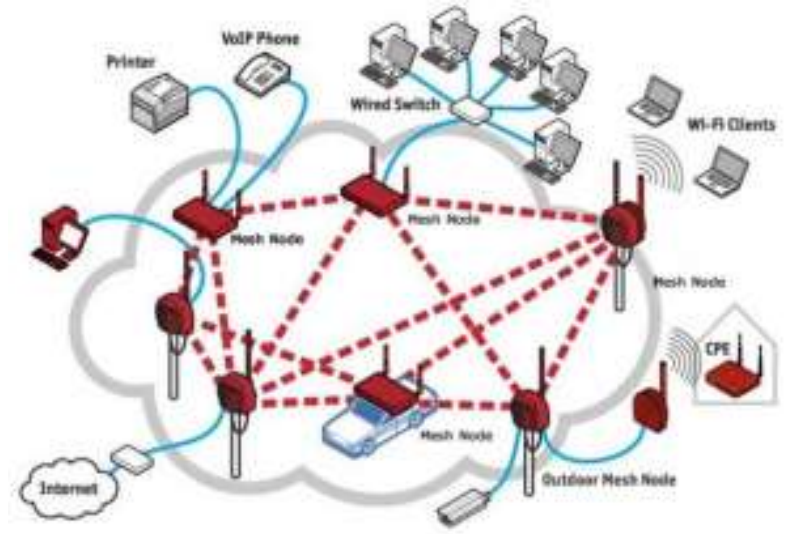

Figure 2: Mesh Network [13] 


\section{An Energy-efficient Smart Street Lighting System with Adaptive Control based on Environment}

Aleksandar et al. proposed the use of a mesh network in the street lighting system [11]. Featured with selfhealing function, the proposed system can perform autorouting in the case of faulty nodes or severe breakdown of communication pathways, by retrying the transfer of data packets or bypassing the malfunction nodes. In the Malaysian context, Yusoff et al. adopted Waspmote, an off-the-shelf solution to implement a WSN-based street light system for controlling and monitoring [14].

Lau et al. proposed an embedded adaptive intelligence algorithm for energy-efficient street lighting where based on the parameters of traffic condition such as the brightness level of street lights is adaptively controlled the traffic volume, travelling speed and geographical location [15]. The authors claimed 30\% energy saving as compared to other methods, and $90 \%$ less energy compared to a conventional scheme.

Marino et al. studied the use of a predictive model in adaptive street lighting control [16]. Based on the traffic dataset obtained, predictive models are developed and tested with the mean absolute percentage error (MAPE) for reliability. The weekly dimming profiles of street lights are defined in accordance with the national and European Unit standards. As a result, the study claimed to have achieved energy saving in the order of $30 \%$.

As pointed out by most reviewed literature, the smart street lighting systems typically share the following requirements and features such as the compliance to rules and regulations for luminaire and safety, costeffectiveness in implementation, ease of installation and maintenance, low operational and life cycle cost and the use of artificial intelligence (AI) for adaptive control. Hence, they become the design considerations of the intelligence street lighting system proposed in this paper.

\section{MATERIALS AND METHODS}

\section{System Architecture}

The mesh topology of WSN offers the flexibility of selfforming and self-healing characteristics. Figure 4 depicts the layout of the WSN communication design of the proposed street lighting system. The topology consists of mesh clients, a mesh master (gateway), a monitoring computer (GUI PC) and the cloud servers connected to the Internet via hypertext transfer protocol (HTTP).

Mesh clients serve to acquire environmental data such as illumination, meteorological and traffic condition. Upon receipt of the data, the mesh clients relay the data to the mesh master via the designated network pathway. Each node has a unique address for identification. Data packets are routed from the node by node manner. By using a mesh network, all nodes are ensured to be accessible in transmission. If one of the nodes is not functioning, the data will go through another path via different nodes until it reaches the receiver.
Mesh master receives the data from the identified nodes and uploads them to the cloud servers for data storage and manipulation. The server also features Web-based GUI and OpenWeatherMap API to acquire meteorological data for illumination level control of the street lighting [17].

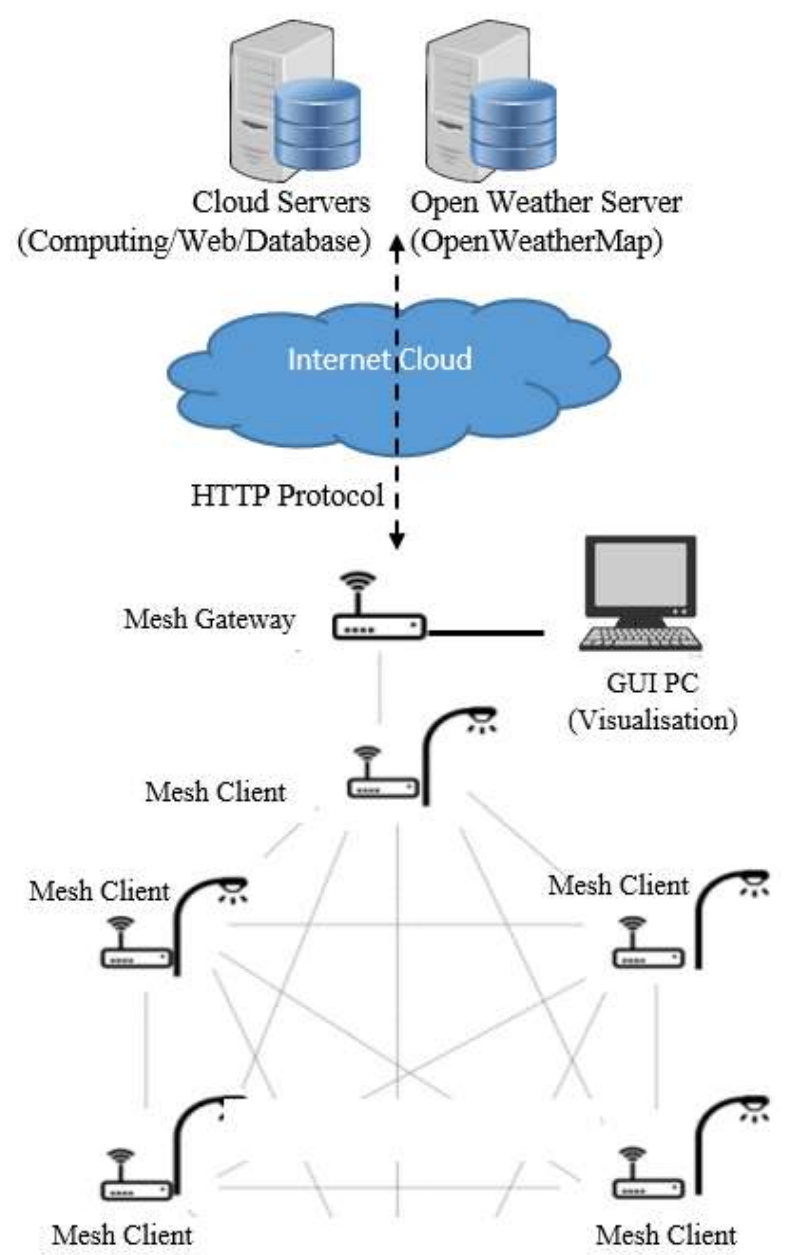

Figure 4: The layout of the wireless network communication and cloud connection

As illustrated in Figure 5, nodes are identified with their node identifications (IDs) and interconnected in a mesh network topology. Each mesh client is to acquire environmental data and perform illumination control. The amalgamated data of illumination, rain and motion data are relayed to the mesh master node for uploading to the cloud servers. In return, a control signal in the form of PWM duty cycle is relayed back to the mesh client via the mesh master for lighting control. The illumination level is triggered by the PWM signal that consequently controls the switching of control devices. All the data from input sensors and control information can be visualised on the GUI of the computer. 


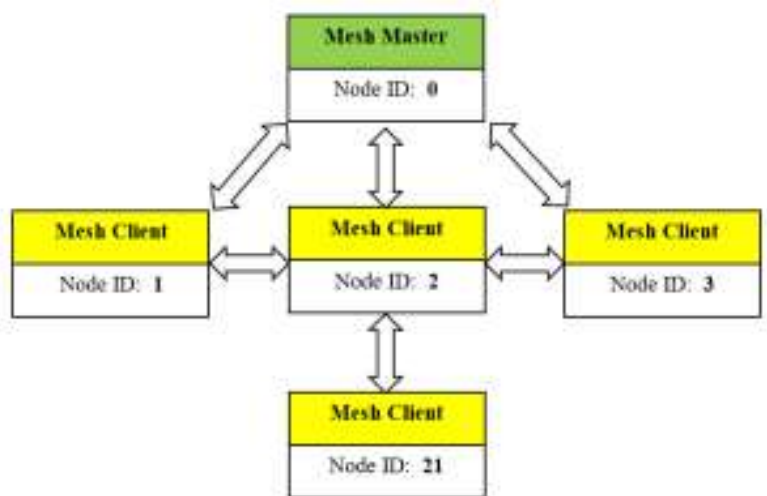

Figure 5: Interconnection of nodes in the mesh network

\section{Design of the Mesh Client and Master Nodes}

Figure 6 shows the design of the mesh client node. The microcontroller is implemented with ATMEGA328P to control the input and output peripherals. A Nordic's RF wireless module, nRF24L01 is used to form the mesh network connecting the master and the client nodes. Sensors connected to the ports of the microcontroller include LDR sensors, current sensors, motion sensors and rain sensors. On the other hand, the PWM control signal used to control the illumination level of street lighting is manipulated according to the control algorithm, as explained in the following section.

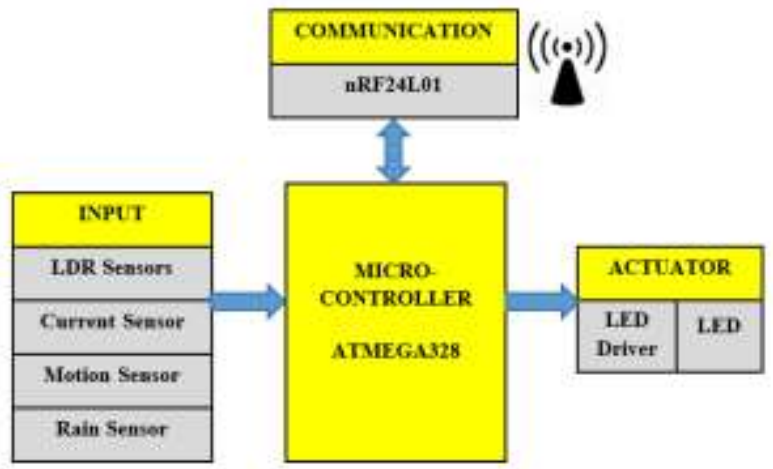

Figure 6:Design of the Mesh Client Node

Figure 7 shows the design of the mesh master node. Real-time clock module in the node provides the microcontroller with real-time information of time and date. The RF module, nRF24L01, is used to connect the mesh network to the server for data communication. The mesh clients, in return, receives the control signal of illumination level manipulated by the cloud servers.

In summary, the illumi nation level of the street lights is environmental-aware, taking into consideration the various sensor data such as motion, meteorological and ambient light. The illumination level is controlled by the PWM control signal generated by a control algorithm, as explained in the following section. Thus, the illumination level is adaptively adjusted in accordance with the actual environment need which in turn optimises the energy consumption of the street lighting system.

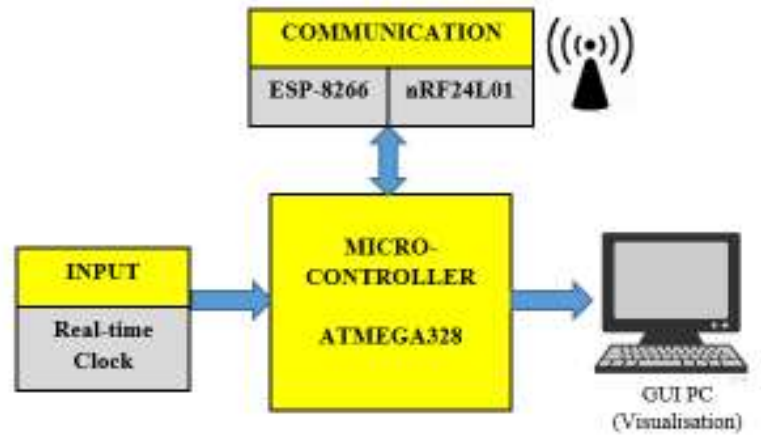

Figure 7: Design of the Mesh Master Node

Furthermore, the GUI of the management computer serves as a platform for easier monitoring and control of the proposed system. The operator can monitor the street lighting system in real-time. The condition of each street light is visually displayed on the operator terminal. Faulty lights can be auto-detected, and site operator will be alerted for immediate maintenance response, reducing the downtime.

\section{Hardware Components}

\section{Microprocessor ATMEGA $328 P$}

In this project, ATMEGA328P, as depicted by the schematic diagram in Figure 8, is used as a controller to control the device for specific tasks programmed. The operating levels are $5 \mathrm{~V}$ and $3.3 \mathrm{~V}$ supplied by voltage regulator $5 \mathrm{~V}, 3.3 \mathrm{~V}$ or USB at pin VCC. It is an 8-bit AVR RISC based microcontroller that comes together with $32 \mathrm{~KB}$ ISP flash memory with read-while-write capabilities, 1024BEEPROM, 2KB SRAM. ATMEGA328P has 6 analog input/output pins, 13 digital input/output pins (6 PWM pins which are $3,5,6,9,10,11)$. The external crystal oscillator used is $16 \mathrm{MHz}$ as standard clock speed.

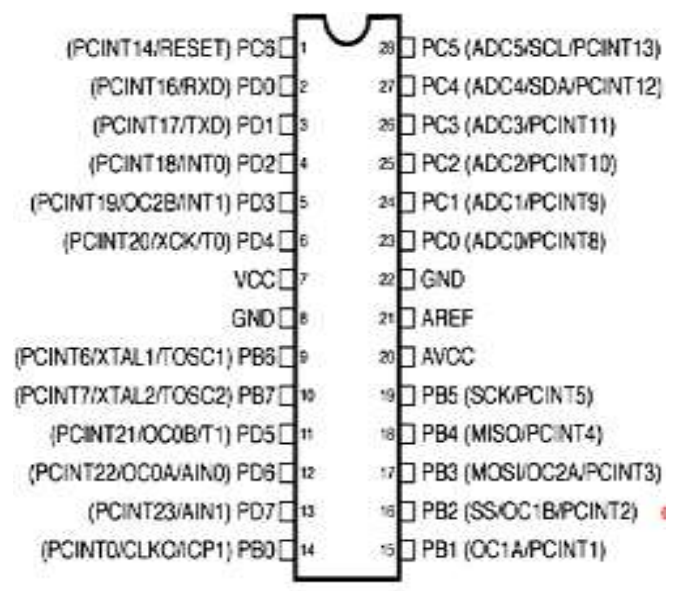

Figure 8: ATMEGA328P Pin Configuration 


\section{PIR Motion Sensor}

Passive infrared (PIR) motion sensor, as depicted in Figure 9, is used to detect the passing of moving vehicles and pedestrians for environment-aware monitoring. Thus, traffic condition, as determined by the PIR data, would then be used to adjust the street lighting intensity intelligently.
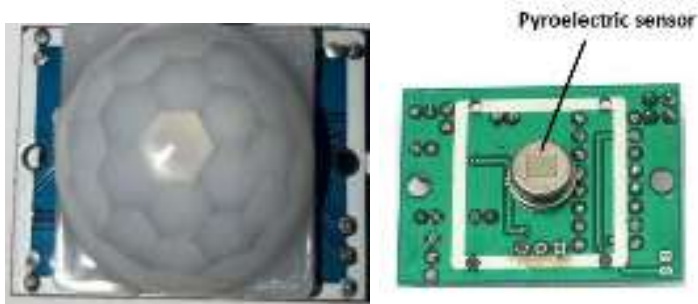

Figure 9: PIR Motion Sensor Module

\section{LDR Sensors}

The function of the light-dependent resistor (LDR) sensors is to detect light intensity based on the variable resistance acquired. For instance, when the light level is high, the resistance of LDR increases or vice versa. In this project, two LDR sensors are used for the sensing of environment light intensity level and the detection of the faulty LED. A typical LDR sensor is illustrated in Figure 10.
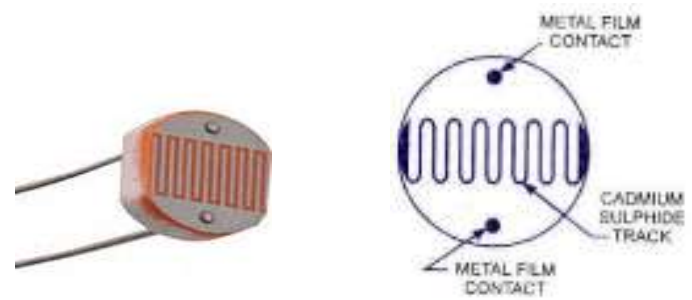

Figure 10: LDR Sensor

\section{Rain/Water Sensor}

Rain/water sensor detects the presence of rainfall and also measures the rainfall intensity. Figure 11 depicts the sensor data used to control the street lighting intensity based on meteorological and control algorithm proposed.

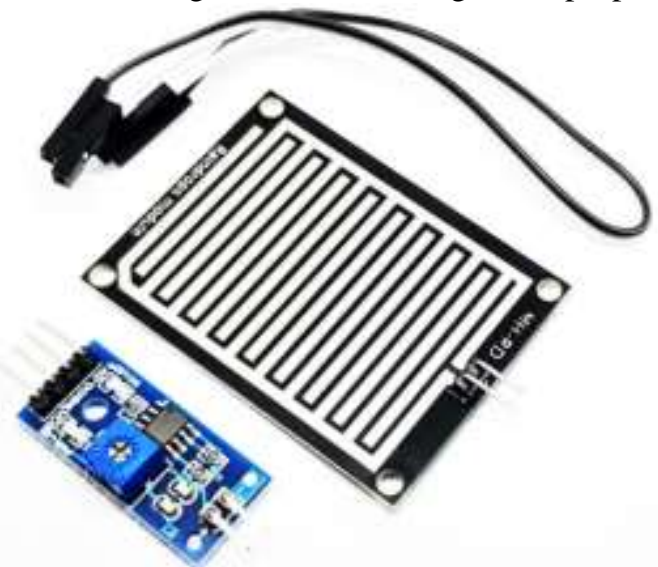

Figure 11: Rain/Water Sensor

\section{Current Sensor}

ACS712is an electrical current sensing device used to measure the electricity consumption of the LED light, as depicted in Figure 12. It also acts as the fault detector of an LED lamp in the system. The electric current data is used to calculate the energy consumption of the proposed system.

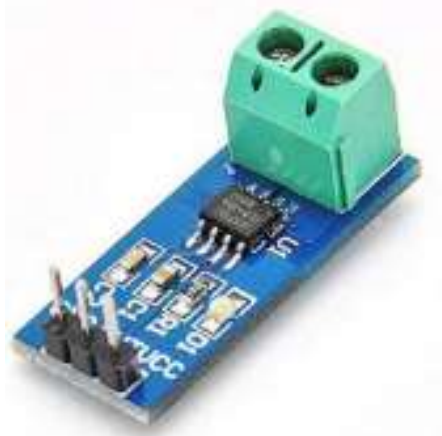

Figure 12: Current Sensor Module

\section{Wireless Network Module}

nRF24L01 RF transceiver module manufactured by the Nordic company, as shown in Figure 13 is used for wireless networking. The data rates available are 250 kbps, $1 \mathrm{Mbps}$, and $2 \mathrm{Mbps}$. nRF24L01 features low-cost hardware and ultra-low power consumption which fits well for wireless network applications.

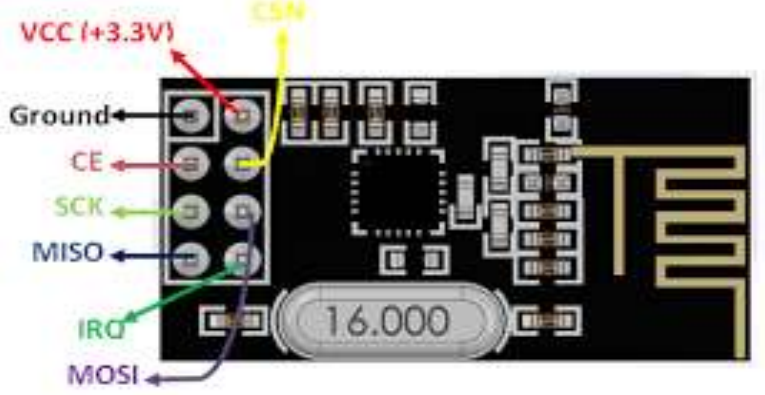

Figure 13: nRF24L01 wireless transceiver module

\section{Street Light Operation Design}

The illumination level of street lights is adjusted automatically according to a novel control mechanism, as depicted in Figure 14. The system is "intelligent" in terms of the ability to control the illumination at either Night-time Mode (energy-saving mode) or Day-time Mode. The system also facilitates asset management based on different environmental conditions with environmental data elicited either from the field sensors or open weather information from the cloud server.

When the system enters the Day-time mode operation from 6:00 am to 6:00 pm, it would generally switch off all the street lights. However, due to safety reason, the system can sense the weather condition and 
switch on the street lights when the ambient light intensity is low during either the cloudy condition or during rain. On the contrary, during the period between 6:00 pm and 6:00 am, the system enters Night-time mode where the energy-saving mechanism will kick in to adjust the illumination level for the attainment of maximum energy-saving. As shown in Table 1, the illumination level (in the unit of Lux) is assigned to the light intensity (in terms of \%) accordingly, for the control mechanism. Table 2 shows the initial settings of the light intensity.

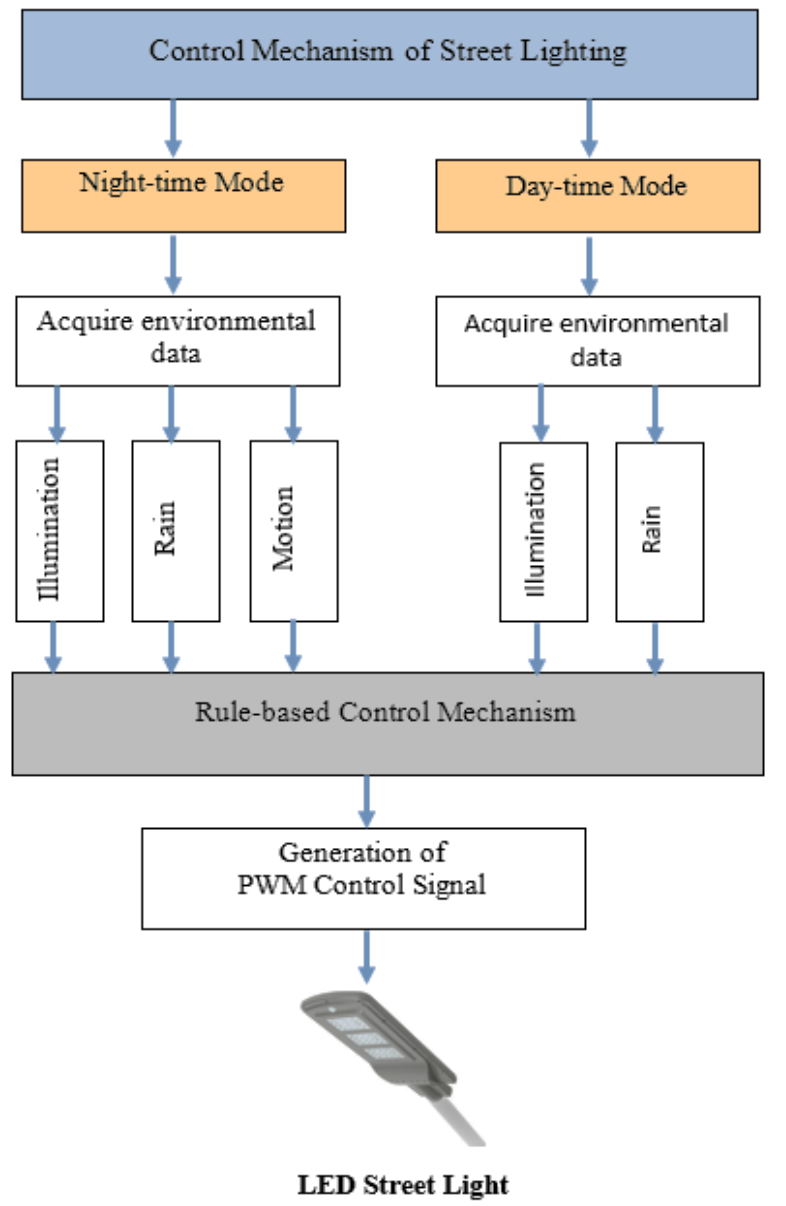

Figure 14: Control Mechanism of the street lighting

As shown in Table 2, the illumination level is set to a minimum level of $20 \%$ without switch off entirely due to the safety regulation imposed [8]. Based on the control mechanism, the illumination setting can be adjusted automatically to the optimum level in correlation with traffic condition and weather condition. For instance, when the traffic condition is low, the illumination is adaptively reduced to the optimum level for energy conservation. During heavy traffic condition or severe environmental condition such as during heavy rain, the illumination is reset to the normal level for safety reason.
For adaptive control, the rule-based control mechanism acquires environmental sensor data, i.e. LDR sensors, and motion sensor, together with the weather information from the cloud server, for the manipulation of illumination level setting. During day time, LDR sensor and rain information are used to detect the environmental condition such as lighting and weather conditions. In the night-time, the weather information and motion sensor data used to sense the traffic conditions are used for adaptive control. The control mechanism performs the manipulation as depicted in Figure 14.

Table 1: Designation of the illumination level with varying light intensity (in \%)

\begin{tabular}{cc}
\hline $\begin{array}{c}\text { Illumination } \\
\text { (in Lux) }\end{array}$ & $\begin{array}{c}\text { Light Intensity } \\
\text { (in \%) }\end{array}$ \\
\hline$<100$ & $50 \%$ \\
$>300$ & $40 \%$ \\
$>500$ & $30 \%$ \\
$>700$ & $20 \%$ \\
$>1000$ & 0 \\
\hline
\end{tabular}

Table 2: Initial Setting of the Light Intensity

\begin{tabular}{lll}
\hline Time & $\begin{array}{l}\text { LED } \\
\text { Status }\end{array}$ & $\begin{array}{l}\text { Light Intensity } \\
\text { (in \%) }\end{array}$ \\
\hline $6 \mathrm{am}-6 \mathrm{pm}$ & OFF & $0 \%$ \\
$6 \mathrm{pm}-7 \mathrm{pm}$ & ON & $20 \%$ \\
$7 \mathrm{pm}-10 \mathrm{pm}$ & ON & $100 \%$ \\
$10 \mathrm{pm}-11 \mathrm{pm}$ & ON & $70 \%$ \\
$11 \mathrm{pm}-12 \mathrm{am}$ & ON & $50 \%$ \\
$12 \mathrm{am}-4 \mathrm{am}$ & ON & $20 \%$ \\
$4 \mathrm{am}-6 \mathrm{am}$ & ON & $50 \%$ \\
\hline
\end{tabular}

\section{Smart Street Light Asset Maintenance System}

The proposed street light asset management system can perform intelligent maintenance of the street light system. It features auto-sensing and diagnostic of the LED lamp against ageing and faulty conditions using a rule-based fault detection mechanism such as shown in Figure 15. For the detection of faulty LED lamps, both LDR sensor and current sensor data are used to diagnose the operational condition of street lights. Suppose a specific LED lamp is set to ON state with the LDR sensor shows low light intensity or no current detected, condition of the lamp of either normal, ageing or faulty state can be deduced. In case of the detection of any faulty lighting, the system will both show notification on the Web-based user interface for visualisation and to site operator for immediate action. Figure 15 depicts the flow of the complete system maintenance mechanism. 


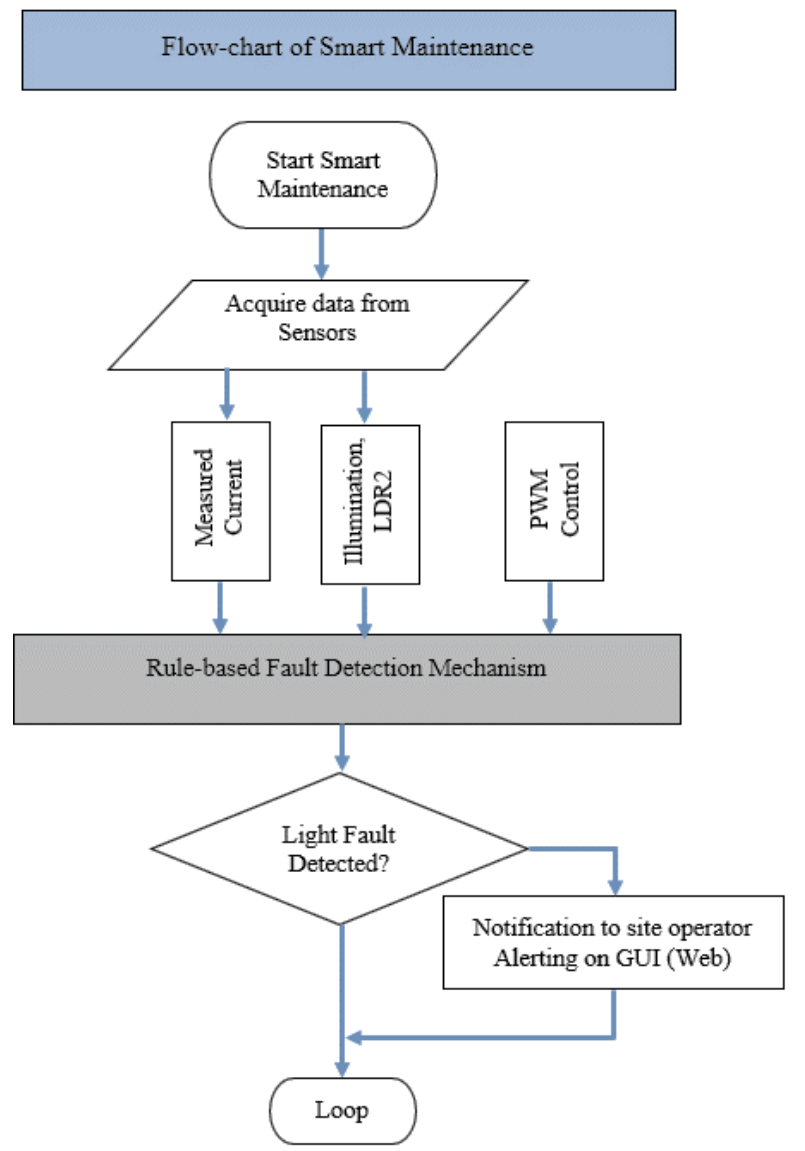

Figure 15: The flow of the Complete System Maintenance Mechanism

\section{RESULTS AND DISCUSSION}

\section{Energy Consumption Metrics}

Energy consumption of the street lighting can be calculated by measuring energy with the kilowatt-hour $(\mathrm{kWh})$ unit, which is equivalent to the amount of $\mathrm{kW}$ electrical appliance used continuously for one hour. Electrical utility billings are charged according to the number of kilowatt-hours of electricity used as the standard measurement of energy consumption. Eq. (1) shows the formula used to calculate energy consumption (in $\mathrm{kWh}$ ) for an electrical appliance with power rating (in $\mathrm{kW}$ ) operates for a duration (in hours).

$$
\begin{aligned}
& \text { Consumedenergy (inkWh) } \\
& =\frac{\text { Powerrating }(\text { inkW) }}{\text { Durationoflighting (inhours) }} . . .
\end{aligned}
$$

\section{Experimental Setup}

Figure 16 shows the prototype of the Mesh Master for experimentation of the control mechanism proposed in this paper. The board consist of timer RTC DS3231, universal serial bus (PL2303), wireless network (nRF24L01), and microprocessor ATmega328P. This board is connected to the computer where the data are transmitted and uploaded to the server for visualisation. The prototype of the proposed system is then fabricated into the PCB board.

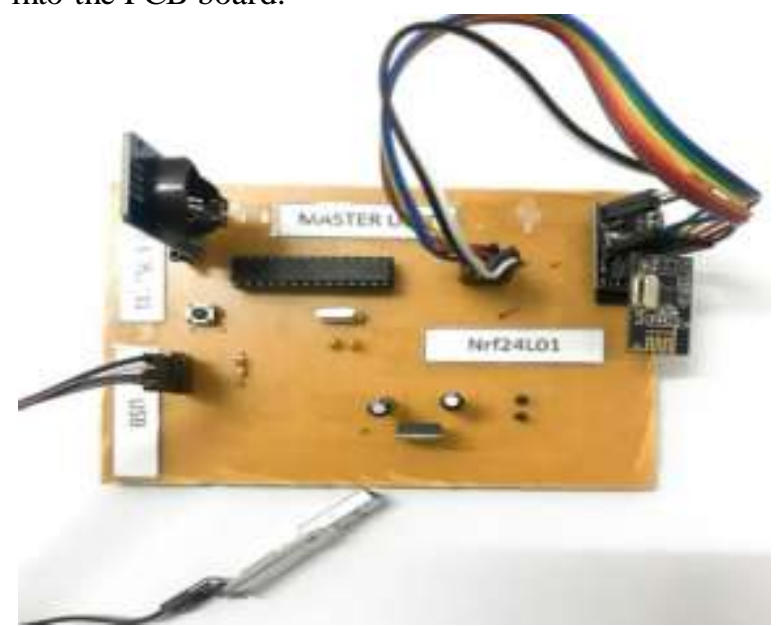

Figure16: The prototype of Mesh Master

Figure 17 depicts the prototype of the mesh client. The board consist of various sensors (LDR, PIR motion, rain, electric current), universal serial bus converter (PL2303), wireless network (nRF24L01), light-emitting diode (LED) and microprocessor ATMEGA328P. In the PCB prototype, sensors which are the inputs of the ATMEGA328P microcontroller include a current sensor, LDR sensor, and PIR motion sensor while LED functions as the output. The intensity of LED lamps is adaptively controlled by the cloud server based on the sensor readings. Wireless sensor network module nRF24L01 enables communication between Master and Client nodes. The parameter data from the input module will be sent to the cloud servers and monitoring GUI PC via the visual interface.

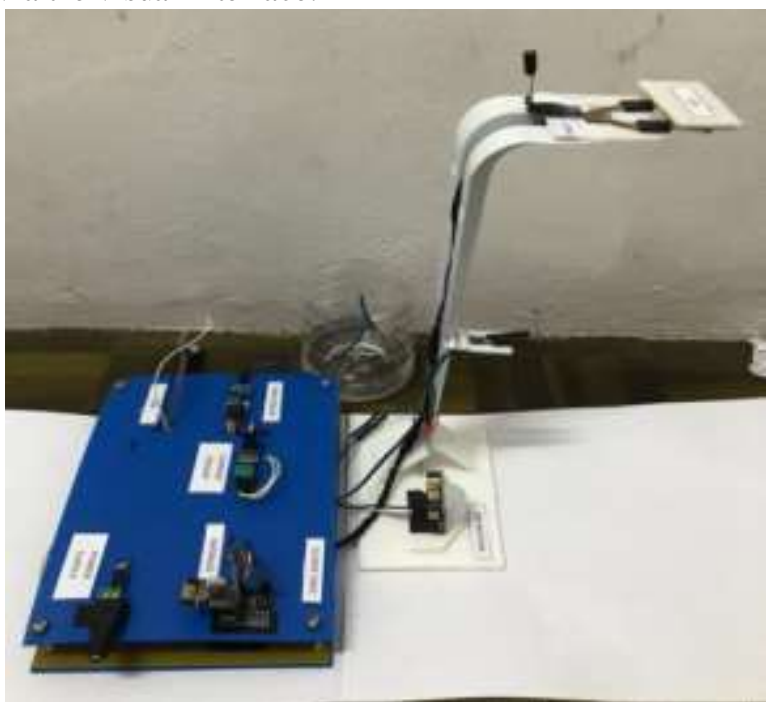

Figure 17: The prototype of Mesh Client 


\section{An Energy-efficient Smart Street Lighting System with Adaptive Control based on Environment}

\section{Visual Interface}

Figure 18 shows the information gathered from the mesh client nodes via the mesh master through WSN displayed via a visual interface programmed with Python, which supports the cross-platform framework.

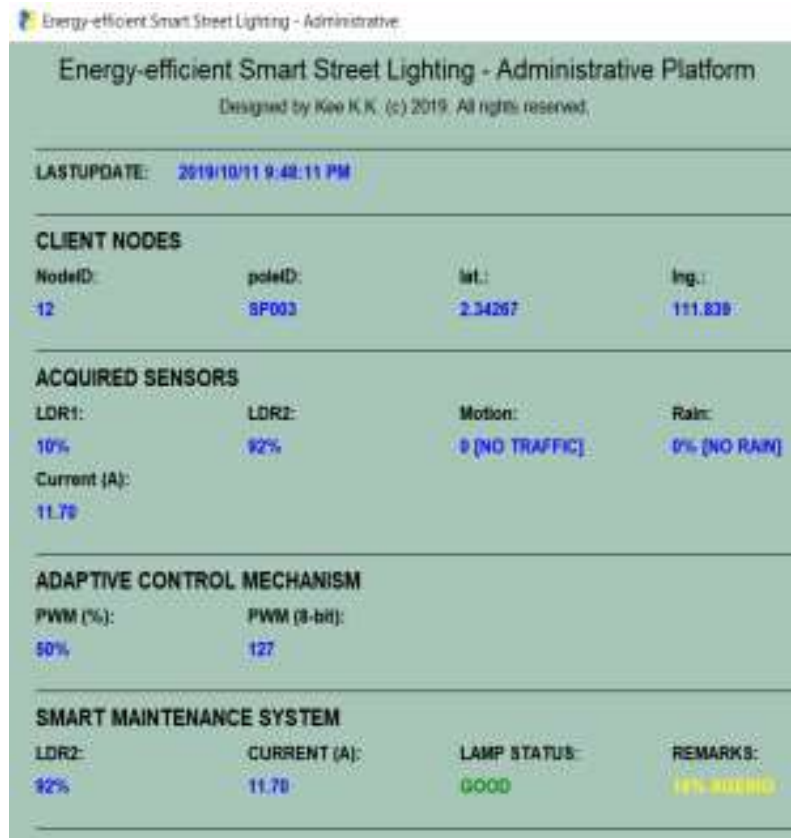

Figure 18: Visual Interface showing the mesh clients information

\section{NodeID and poleID}

Node ID is a unique identification number assigned to each mesh client by the mesh master. Node ID $=0$ is automatically assigned to the mesh master. In this project, the mesh network is implemented for flexible self-healing and self-forming. Each nodeID is assigned to a poleID which represents a physical location of the street light pole.

\section{LDR1 and LDR2 Sensors}

LDR1 sensor senses the cloudy or bright weather in the daytime and is used to adjust the illumination output of the LED. Placed in mesh client as an input, LDR1 sensor acquires light intensity data for the determination of the lighting required by the setting of control PWM signal. Thus, the LED lighting is continuously and adaptively controlled. The LDR1 sensor is utilised during the period of 6 am to $6 \mathrm{pm}$ for the detection of weather condition. Table 3 shows the setting of the PWM control signals according to the corresponding LDR1 values. On the other hand, LDR2 is used for smart asset maintenance purpose for street lighting. Placed with LED lamp of the mesh client, it senses and acquires illumination level of the LED lamp in order to evaluate its operational condition.
Table 3: Normalized LDR1 valuesand corresponding PWM signals

\begin{tabular}{ll}
\hline $\begin{array}{l}\text { LDR1 value } \\
\text { (normalised unit) }\end{array}$ & $\begin{array}{l}\text { PWM signal } \\
\text { (in \% of duty cycle) }\end{array}$ \\
\hline$<=150$ (dim) & $50 \%$ \\
\hline & \\
$<=330$ & $40 \%$ \\
$<=550$ & $30 \%$ \\
$<=700$ & $20 \%$ \\
$<=1023$ (bright) & 0 \\
\hline
\end{tabular}

PIR Motion Sensor and Rain Sensor

Passive red infrared (PIR) sensor is used to sense the traffic condition in nighttime and adjust the illumination level of the LED lighting. A rain sensor is used to detect the normal or raining condition. Placed in the mesh client, both PIR and rain sensors collect the relevant data and upload to the cloud server via mesh master node. Upon receipt of the PWM control signal from the cloud server, the mesh clients control the illumination level of the LED lamp attached accordingly. The sensors remain active during the energy-saving mode at 12 am until 4 am where the illumination level will be at as the default setting of $20 \%$, and increasing up to $75 \%$ depending on the traffic condition, as depicted in Table 4.

Table 4. Values of PIR Motion detection and the corresponding PWM signal

\begin{tabular}{lll}
\hline $\begin{array}{l}\text { PIR Motion } \\
\text { (in 1 or 0) }\end{array}$ & $\begin{array}{l}\text { PWM signal } \\
\text { (in \% of duty cycle) }\end{array}$ & Status \\
\hline HIGH $(1)$ & $75 \%$ & "Traffic is High" \\
LOW $(0)$ & $20 \%$ & "Traffic is Low" \\
\hline
\end{tabular}

$P W M$

Pulse width modulation (PWM) signal is used to control the illumination level of the LED. Upon the receipt of sensor data from the mesh clients, the server manipulates and issues PWM control signals based on the proposed control algorithm. With this, the LED lamp is calibrated to different illumination levels (in \% of nominal value) in response to different PWM control signal rates, as depicted in Table 5.

Table 5: PWM Control signal VS Illumination output

\begin{tabular}{ll}
\hline $\begin{array}{l}\text { PWM } \\
\text { (normalised unit) }\end{array}$ & $\begin{array}{l}\text { Illumination Output } \\
\text { (in \% of nominal value) }\end{array}$ \\
\hline 51 & $20 \%$ \\
127 & $50 \%$ \\
179 & $70 \%$ \\
255 & $100 \%$ \\
\hline
\end{tabular}




\section{An Energy-efficient Smart Street Lighting System with Adaptive Control based on Environment}

\section{Smart Maintenance System}

LDR2 and current sensor data are used to determine the operational condition of the LED lamp. Placed with the LED lamp, LDR2 senses the illumination level of the LED lamp in the mesh client. The illumination level, together with the current consumption data, are relayed to the server for maintenance purposes such as the detection of ageing or faulty LED lamp in the network of street light system. Figure 19 depicts the smart maintenance visual interface displaying the operational parameters and the status (diagnosed by the system). The LED lamp condition is determined automatically by the system for decision support purpose. Hence, the maintenance work of street light replacement is made more accessible and managed more intelligently with real-time remote control and monitoring.

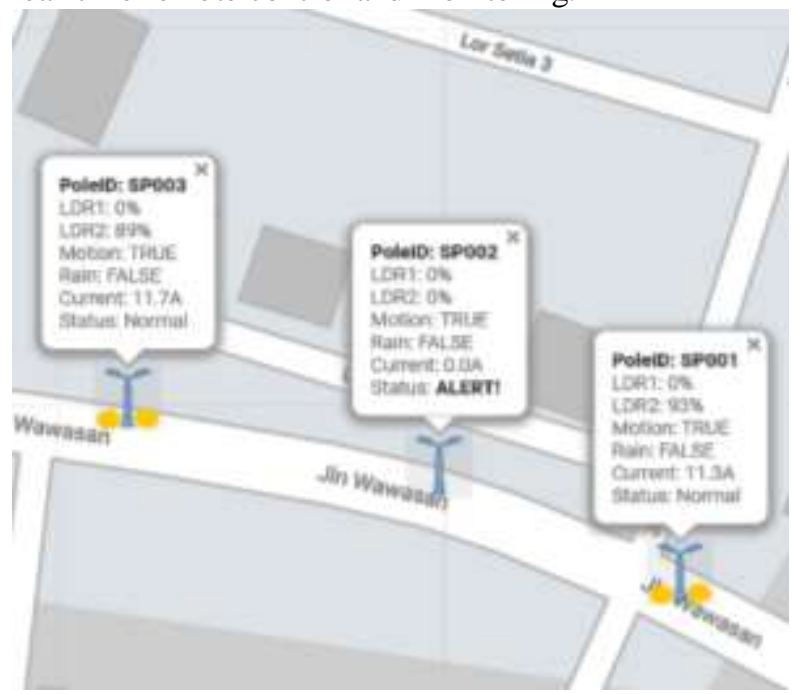

Figure19: Real-time condition of LED lamps for maintenance purpose

\section{Quantitative Analysis}

Figure 20 depicts the time-series illumination output versus time (in 15-minute slots) of a case study elicited from the street lights installed at Jalan Wawasan, near University College of Technology Sarawak (UCTS), Sibu. The power rating is adaptively set according to the NightTime mode from $6 \mathrm{pm}$ to $6 \mathrm{am}$ for the demonstration of an energy-saving purpose. The traffic condition from $6 \mathrm{pm}$ to $7 \mathrm{pm}$ is relatively low compared to the traffic from $7 \mathrm{pm}$ to $10 \mathrm{pm}$. Then the traffic slowly decreases gradually from $10 \mathrm{pm}$ until 1 am and stays almost the same for the wee hour of the morning. The weather condition is clear without raining. The energy consumed by the LED lamp is 6 watts, supplied by 5 volts direct current (DC), is calculated by Eq (1).

There is a total of 72.0 Wh energy consumption for the case of an ordinary street light system for 12 hours. On the contrary, as depicted in Table 6, it is found that the proposed smart street lighting system achieved up to
$48.43 \%$ energy-saving with the control algorithm implemented.

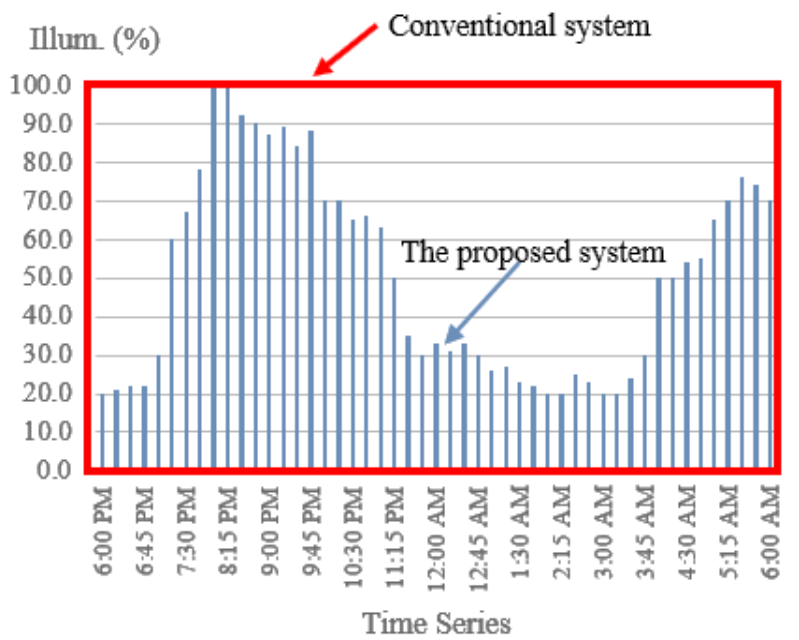

Figure 20: Illumination output for 12-hour interval

There is a total of 72.0 Wh energy consumption for the case of an ordinary street light system for 12 hours. On the contrary, as depicted in Table6, it is found that the proposed smart street lighting system achieved up to $48.43 \%$ energy-saving with the control algorithm implemented.

Table 6. Quantitative Result

\begin{tabular}{cccc}
\hline Time & $\begin{array}{c}\text { Illum. } \\
\text { (in \%) }\end{array}$ & $\begin{array}{c}\text { Energy } \\
\text { Cons. } \\
\text { (Wh) }\end{array}$ & $\begin{array}{c}\text { Energy } \\
\text { Saving } \\
\text { (Wh) }\end{array}$ \\
\hline 6:00 PM & 20.0 & 0.30 & 1.20 \\
6:15 PM & 21.0 & 0.32 & 1.19 \\
6:30 PM & 22.0 & 0.33 & 1.17 \\
6:45 PM & 22.0 & 0.33 & 1.17 \\
$:$ & $:$ & $:$ & $:$ \\
5:15 AM & 77.0 & 1.16 & 0.35 \\
5:30 AM & 76.0 & 1.14 & 0.36 \\
5:45 AM & 74.0 & 1.11 & 0.39 \\
6:00 AM & 70.0 & 1.05 & 0.45 \\
\cline { 2 - 4 } & Total & $\mathbf{3 7 . 9} \mathbf{W h}$ & $\mathbf{3 5 . 6 ~ W h}$ \\
\cline { 2 - 4 }
\end{tabular}

\section{CONCLUSION}

The project aims to design and develop a smart street lighting system based on wireless sensing network technology for benefits energy saving and ease of maintenance. The LED light source is used to ensure maximum energy efficiency in lighting while adaptive control algorithm based on environment data is employed to maximise energy-saving further. In the adaptive mode, the illumination level of lighting can be monitored and adjusted based on environment data for 
An Energy-efficient Smart Street Lighting System with Adaptive Control based on Environment

energy conservation. Furthermore, LDR sensors are also used to determine the real-time illumination level of LED light, apart from the detection of faulty LED unit for maintenance purpose. Thus, the proposed system offers more efficient and proactive maintenance compared to standard manual inspection of the street lights.

Based on the experimental results, the proposed system has a potential of energy-saving up to $48 \%$, as compared to the conventional LED street lighting systems. It implies that the proposed design of the street lighting system has both environmental conservation benefits in reducing $\mathrm{CO}_{2}$ emissions, and in cost reduction. Besides, this system also facilitates easy maintenance of the street lights with the detection of faulty units. To further this work, data analytics feature is to be incorporated in this system to enhance the intelligence of the system, setting the agenda for the development of a full-fledged internet of things (IoT) system.

\section{ACKNOWLEDGMENT}

This work is fully funded by UCTS Research Grant (Project ID: UCTS/RESEARCH/3/2018/13) of University College of Technology Sarawak.

\section{REFERENCES}

[1] "What is a Smart City? - Definition from Techopedia." [Online]. Available: https://www.techopedia.com/definition/31494/s mart-city\#targetText=A smart city is a,consumption $\% 2 \mathrm{C}$ wastage and overall costs. [Accessed: 16-Oct-2019].

[2] "LED street lighting: Unburdening our cities," World Bank Blogs. [Online]. Available: https://blogs.worldbank.org/energy/led-streetlighting-unburdening-our-cities. [Accessed: 16Oct-2019].

[3] Z. Ar, "Revised 11th Malaysia Plan combats climate change," 2016.

[4] "Street and Public Lighting | Energy Rating." [Online]. Available: http://www.energyrating.gov.au/products/lighti ng/street. [Accessed: 21-Oct-2019].

[5] Y. M. Yusoff, R. Rosli, M. U. Karnaluddin, and M. Samad, "Towards smart street lighting system in Malaysia," in 2013 IEEE Symposium on Wireless Technology \& Applications (ISWTA), 2013, pp. 301-305.

[6] "Energy Efficiency in Streetlighting and
Transport Infrastructure Reference Material for Competence."

[7] "Addendum No. 1: Revision 1 to L S20 Specification for Road Lighting InstallationAugust-1999.pdf." [Online]. Available: https://jmal.jkr.gov.my/. [Accessed: 22-Oct2019].

[8] Malaysian Standard, MS825 Part 1 (Code of Practice for the Design of Road Lighting - Part 1: Lighting of Roads and Public Amenity Areas). 2007.

[9] F. Bellido-Outeiriño, F. Quiles-Latorre, C. Moreno-Moreno, J. Flores-Arias, I. MorenoGarcía, and M. Ortiz-López, "Streetlight Control System Based on Wireless Communication over DALI Protocol," Sensors, vol. 16, no. 5, p. 597, Apr. 2016.

[10] R. F. Fernandes, C. C. Fonseca, D. Brandao, P. Ferrari, A. Flammini, and A. Vezzoli, "Flexible Wireless Sensor Network for smart lighting applications," in 2014 IEEE International Instrumentation and Measurement Technology Conference (I2MTC) Proceedings, 2014, pp. 434-439.

[11] Aleksandar Kospenda, "Wireless Sensor Network for Smart Street Lighting System," University of Iceland, 2017.

[12] P. Elejoste et al., "An easy to deploy street light control system based on wireless communication and LED technology," Sensors (Switzerland), vol. 13, no. 5, pp. 6492-6523, May 2013.

[13] P. Elejoste et al., "Easily Deployable Streetlight Intelligent Control System Based on Wireless Communication," Springer, Berlin, Heidelberg, 2012, pp. 334-337.

[14] Y. M. Yusoff, R. Rosli, M. U. Karnaluddin, and M. Samad, "Towards smart street lighting system in Malaysia," in IEEE Symposium on Wireless Technology and Applications, ISWTA, 2013, pp. 301-305.

[15] S. P. Lau, G. V. Merrett, and N. M. White, "Energy-efficient street lighting through embedded adaptive intelligence," in 2013 International Conference on Advanced Logistics and Transport, ICALT 2013, 2013, pp. 53-58.

[16] F. Marino, F. Leccese, and S. Pizzuti, "Adaptive Street Lighting Predictive Control," in Energy Procedia, 2017, vol. 111, pp. 790-799.

[17] "Weather API - OpenWeatherMap." [Online]. Available: https://openweathermap.org/api. [Accessed: 31-Oct-2019]. 